\title{
Prediction of width of un-erupted incisors, canines and premolars in a Ugandan population: A cross sectional study
}

\author{
William Buwembo ${ }^{1 *}$, Annet Kutesa ${ }^{2}$, Louis Muwazi ${ }^{2}$ and Charles Mugisha Rwenyonyi ${ }^{2}$
}

\begin{abstract}
Background: Accurate prediction of the space forms an important part of an orthodontic assessment in the mixed dentition. However the most commonly used methods of space analysis are based on data developed on Caucasian populations. In order to provide more accurate local data we set out to develop a formula for predicting the widths of un-erupted canines and premolars for a Ugandan population and to compare the predicted widths of the teeth from this formula with those obtained from Moyers' tables, and Tanaka and Johnston's equations.

Methods: Dental casts were prepared using mandibular and maxillary arch impressions of 220 children (85 boys/ 135 girls) aged 12-17 years recruited from schools in Kampala, Uganda. The mesio-distal width of the mandibular incisors, mandibular and maxillary canines and premolars were measured with a pair of digital calipers. Based on regression analysis, predictive equations were derived and the findings were compared with those presented in Moyers' probability tables, and Tanaka and Johnston's equations.

Results: There were no statistically significant differences between the tooth widths predicted by our equations and those from Moyers' probability tables at the $65^{\text {th }}$ and $75^{\text {th }}$ percentile probabilities for the girls and at $75^{\text {th }}$ level in boys in the mandibular arch. While in the maxillary arch no statistically significant differences at the $75^{\text {th }}$ and $95^{\text {th }}$ levels were noted in girls. There were statistically significant differences between predicted tooth sizes using equations from the present study and those predicted from the Tanaka and Johnston regression equations.

Conclusions: In this Ugandan population, Moyers' probability tables could be used to predict tooth widths at specific percentile probabilities, but generally, Tanaka and Johnston technique tends to overestimate the tooth widths.
\end{abstract}

Keywords: Canines, Incisors, Mesio-distal widths, Prediction equation, Premolars, Ugandan

\section{Background}

Accurate prediction of the space available to accommodate the un-erupted canines and premolars forms an important part of an orthodontic assessment in the mixed dentition [1-4] as it is reported to assist dental practitioners to determine the treatment options for the patients [2]. Different methods have been employed to predict space for un-erupted teeth [3-17]. The most commonly used methods are Moyers' probability tables [5] and the prediction equation of Tanaka

\footnotetext{
* Correspondence: wbuwembo@yahoo.com

'Department of Anatomy, College of Health Sciences, Makerere University, Kampala, Uganda

Full list of author information is available at the end of the article
}

and Johnston [14]. However, these methods were developed on Caucasian populations and their predictive accuracy on populations from other races is doubtful [17-23]. Consequently, this led to development of prediction equations and probability tables for different populations [19,20,24-26]. So far we have not come across any information regarding development of formulae for predicting widths of un-erupted teeth in a Ugandan population. The purpose of this study was to develop a formula for predicting the widths of unerupted canines and premolars in a Ugandan population and to compare the predicted values with those obtained from methods developed by Moyers [5], and Tanaka and Johnston [14].

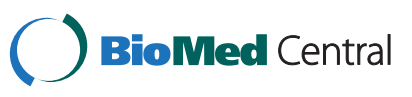




\section{Methods}

\section{Study design}

This was a cross sectional study based on casts of the mandibular and maxillary arches

\section{Study area}

The study areas were 5 secondary schools within a radius of $6 \mathrm{~km}$ from Makerere University College of Health Sciences, the affiliate institution of the investigators. The 5 study schools were randomly selected from a list of 35 schools using numbers.

\section{Study population}

The study sample comprised school children $(n=220)$ aged 12 - 17 years who had all permanent teeth erupted except third molars. All the children who were Ugandans of African descent in the above age range were requested to make two lines according to sex. They were systematically randomly selected. Every $5^{\text {th }}$ child was selected from the line, totaling 232 children. The children were clinically examined for dentition status and those who had crowded, spaced, malformed or missing (except third molar) teeth, inter-proximal caries, interproximal restorations or had history of orthodontic treatment were excluded. The children were excluded as they were assumed not to have normal contact points on proximal tooth surfaces. Twelve children were thus excluded leaving a sample of 220 children (85 boys/135 girls).

\section{Ethical issues}

Permission to carry out the study was obtained from Makerere University Medical School Research and Ethics Committee and the respective school authorities. The purpose of the study was explained to the parents/ guardians and the children in accordance with Helsinki Declaration [27]. Written consent was obtained from the parents/guardians of the children. All the children assented to the study and were recruited.

\section{Study dental casts}

Each child's impressions of mandibular and maxillary arches were taken using disposable dental trays (Acumen Surgical Pvt Ltd, Barcelona, Spain) and sodium alginate impression material (Kromopan Lascod Spa, Italy). The impressions for each child were wrapped in wet cotton wool and kept in a separate polythene bag with an identification number and then transported within $2 \mathrm{~h}$ to the dental laboratory in the Department of Dentistry, Makerere University College of Health Sciences for casting. On average, the impressions were poured into casts using dental stone (Gypsano LLC, Fujariah, United Arab Emirates) within $6 \mathrm{hr}$. The casts were let to set for $3 \mathrm{~h}$ before separating them from the impressions. The respective identification number was inscribed on each pair of dental casts.

\section{Measurement of tooth mesio-distal width}

In order to provide for reliability and consistency in tooth width measurements, one of the investigators (WB) did all the measurements on the dental casts with a pair of digital sliding vernier calipers (Mitutoyo, Southampton, U.K) in natural light as described by Hixon and Oldfather [11]. The mesio-distal widths of the teeth were obtained by measuring the greatest distance between the contact points on proximal tooth surfaces $[11,28]$. The mesio-distal width of the four mandibular permanent incisors, maxillary and mandibular canines and premolar teeth were measured. The measured values were corrected to the nearest $0.01 \mathrm{~mm}$ and recorded onto a data sheet with their corresponding identification numbers.

\section{Reliability test}

Blind duplicate measurement of the tooth widths in $10 \%$ $(n=22)$ of the dental casts was done to assess reproducibility at an interval of 1 week. This was based on systematic random selection of every $10^{\text {th }}$ cast (mandibular and maxillary) from the sample. The intraclass correlation coefficients were calculated to check for consistency [29] in the measurement of tooth widths on the 22 sets of dental casts. The agreement was almost perfect with correlation coefficients between 0.84 and 0.93 for summations of mandibular incisors and all four sets of canine and premolar widths.

\section{Data analysis}

The data were entered into a computer and analysed using Statistical Package for Social Sciences Inc. (SPSS version 15.0 for Windows, Illinois, USA). Frequency distributions were used to describe the material and the data assumed a normal distribution. Student's $t$ test for independent samples was used to assess any significant difference: (i) between the sums of the mesiodistal diameter of permanent: (a) incisors, (b) canine and first and second premolars, canine and first and second premolars in male and female subjects, and (ii) between the regression values using Moyers' probability tables [5] and the Tanaka and Johnston equation [14] with the actual canine and premolars width measurements. Bivariate analyses and linear regression analyses were performed between the predicted and actual tooth size for the Tanaka and Johnston prediction equation [14]. The following predictive formula was derived: $\mathrm{Y}=\mathrm{a}+\mathrm{b}(\mathrm{x})$, where $\mathrm{Y}$ was the predicted sum of widths of the canine and premolars in one quadrant; $\mathrm{x}$ was the measured width of the mandibular incisors while $a$ and $b$ were constants. The interclass correlation for parametric data was used to check for reproducibility in measuring the 
tooth widths. The level of significance was set at 5\%. The values of the sum of the canines and premolars obtained using the derived prediction formulae were compared with the predicted values obtained with Moyers' probability tables [5], and the Tanaka and Johnston's prediction equation [14].

\section{Results}

The study population comprised of 220 children aged 1217 years (mean, $14.6 \pm 3.5$ years). The width of maxillary and mandibular canine and premolars was significantly higher in the boys as compared to girls ( $\mathrm{p}<0.05, t$ test; Table 1). There was a significant correlation between the mandibular incisors, and sum of the maxillary canine and premolars, and the sum of the mandibular canine and premolars ( $\mathrm{p}<0.05, t$ test; Table 2 ). The overall regression coefficient of mandibular canine and premolars was 0.83 and for maxillary canine and premolars was 0.78 (Table 2). The standard error of estimate ranged from 0.30 to $0.52 \mathrm{~mm}$ with the errors smaller in girls as compared to boys (Table 2). The values of regression coefficient $b$ ranged from 0.54 to 0.68 and were all significantly different ( $\mathrm{p}<0 \cdot 05, t$ test). Tables 3 and 4 show the differences between the sizes of canine and premolars widths obtained using the regression equations from the present study and the predicted widths of canine and premolars for mandibular and maxillary arches derived from Moyers' probability tables [5] at different probability levels, respectively. There were no statistically significant differences between the sizes predicted by the equations and the predicted widths from Moyers' probability tables [5] at the $65 \%$ level for the boys and $75 \%$ level for the girls in the mandibular arch $(\mathrm{p}>0.05, t$ test; Table 3$)$. In the maxillary arch, no significant difference between the sizes predicted by the equations and the predicted widths from Moyers' probability tables [5] at $75^{\text {th }}$ level in boys and at $75^{\text {th }}$ and $95^{\text {th }}$ levels in the girls ( $\mathrm{p}>0.05 \%, t$ test; Table 4 ). The difference $(\mathrm{mm})$ between the regression values derived using the equations from the present study of the sum of the canine and premolars of Ugandan children and those predicted from Tanaka and Johnston equations [14] for same subjects in the mandibular and maxillary arches is presented in Table 5. There were statistically significant differences between predicted widths using equations from the present study compared to Tanaka and Johnston regression equations [14] ( $\mathrm{p}<0.05, t$ test; Table 5).

\section{Discussion}

Prediction of the width of un-erupted teeth in a population based on values from another race is likely to provide inaccurate estimates $[18,19,23,24]$. This may be attributed to racial differences in tooth sizes [25]. Data to provide such equations for a Ugandan population for the first time were generated in the present study. The correlation coefficients between the width of the mandibular incisors, mandibular and maxillary canines and premolar teeth ranged from 0.77 to 0.84 (Table 2) using the derived prediction formulae. Our correlation coefficients were higher compared to those from Hong Kong Chinese ( $r=0.58$ to 0.66 ) [19], Jordanian ( $r=.60$ to 0.66 ) [28], Syrian ( $r=0.58$ to 0.66) [26] and the Pakistan population $(r=.64$ to 0.67$)$ [30]. Comparable to our findings, a study from a Brazilian population [31] found a correlation value of 0.81 . The differences in correlation values may be due to the genetic influence on the tooth sizes $[25,30]$. We also found a sex difference in the correlation values which may partly be attributed to the size of the canines and premolars in the maxillary and mandibular arches (Table 1) as previously reported [30].

In the present study, the slope of the simple linear regression equation ranged from 0.54 for the maxillary teeth in the boys to 0.68 for the mandibular teeth in the girls (Table 2). These values are comparable to those reported for the African American [17,32], Thai [33], Hong Kong Chinese [19], Senegalese [34], Saudi [18] and Jordanian populations [28].

Table 1 The measurement of the sum of mesiodistal width of the mandibular incisors, mandibular and maxillary canines and premolar teeth $(\mathrm{mm})$ according to sex of the children

\begin{tabular}{|c|c|c|c|c|}
\hline Sex & Tooth group & Mean & S.D & Standard error of mean \\
\hline \multirow[t]{3}{*}{ Girls $(n=135)$} & Mandibular incisors & 20.99 & 2.34 & 0.202 \\
\hline & Mandibular canines and premolars & 19.99 & 1.89 & 0.163 \\
\hline & Maxillary canines and premolars & 20.53 & 1.71 & 0.140 \\
\hline \multirow[t]{3}{*}{ Boys $(n=85)$} & Mandibular incisors & 21.53 & 2.49 & 0.270 \\
\hline & Mandibular canines and premolars & 20.62 & 1.94 & 0.210 \\
\hline & Maxillary canines and premolars & 21.05 & 1.76 & 0.191 \\
\hline \multirow[t]{3}{*}{ Total $(n=220)$} & Mandibular incisors & 21.20 & 2.41 & 0.163 \\
\hline & Mandibular canines and premolars & 21.24 & 1.93 & 0.130 \\
\hline & Maxillary canines and premolars & 20.73 & 1.75 & 0.118 \\
\hline
\end{tabular}


Table 2 Regression parameters for the prediction equations of the sum of widths of un-erupted mandibular and maxillary canine and premolar teeth according to sex of the children

\begin{tabular}{|c|c|c|c|c|c|c|c|}
\hline \multirow[b]{2}{*}{ Sex } & \multirow[b]{2}{*}{ Tooth group } & \multirow[b]{2}{*}{$\mathbf{r}$} & \multicolumn{2}{|c|}{ Regression coefficient } & \multirow[b]{2}{*}{ 95\% Confidence interval } & \multirow[b]{2}{*}{ SEE } & \multirow[b]{2}{*}{ P-value } \\
\hline & & & a & B & & & \\
\hline \multirow[t]{2}{*}{ Girls $(n=135)$} & Mandibular canines and premolars & 0.84 & 5.73 & 0.68 & $0.61-0.75$ & 0.37 & $<0.001$ \\
\hline & Maxillary canines and premolars & 0.79 & 8.49 & 0.57 & $0.50-0.65$ & 0.39 & $<0.001$ \\
\hline \multirow[t]{2}{*}{ Boys $(n=85)$} & Mandibular canines and premolars & 0.79 & 7.34 & 0.62 & $0.51-0.72$ & 0.52 & $<0.001$ \\
\hline & Maxillary canines and premolars & 0.77 & 9.32 & 0.54 & $0.45-0.64$ & 0.50 & $<0.001$ \\
\hline \multirow[t]{2}{*}{ Combined $(n=220)$} & Mandibular canines and premolars & 0.83 & 6.25 & 0.66 & $0.60-0.72$ & 0.31 & $<0.001$ \\
\hline & Maxillary canines and premolars & 0.78 & 8.72 & 0.57 & $0.51-0.63$ & 0.30 & $<0.001$ \\
\hline
\end{tabular}

SEE, Standard error of estimate; r, Coefficient of correlation; $a$ and b, Linear regression constants.

Table 3 The mean difference (in $\mathrm{mm}$ ) between the predicted values of of the mandibular canines and premolar teeth from the present study and those predicted from Moyers' tables [5] for the same subjects at deferent percentiles (5-95\%)

\begin{tabular}{|c|c|c|c|c|c|c|c|c|}
\hline \multirow{2}{*}{$\begin{array}{l}\text { Percentile } \\
\text { probability } \\
\text { (\%) }\end{array}$} & \multicolumn{4}{|l|}{ Girls $(n=135)$} & \multicolumn{4}{|l|}{ Boys $(n=85)$} \\
\hline & Mean difference $(\mathrm{mm})$ & SD & $95 \% \mathrm{Cl}$ & P-value & Mean difference $(\mathrm{mm})$ & SD & $95 \% \mathrm{Cl}$ & P-value \\
\hline 5 & -2.66 & 0.28 & $-2.84--2.48$ & $<0.001$ & 2.32 & 0.29 & $2.13-2.51$ & $<0.001$ \\
\hline 15 & -1.93 & 0.28 & $-2.11--1.75$ & $<0.001$ & 1.61 & 0.30 & $1.42-1.80$ & $<0.001$ \\
\hline 25 & -1.50 & 0.27 & $-1.67--1.32$ & $<0.001$ & 1.16 & 0.28 & $0.98-1.34$ & $<0.001$ \\
\hline 35 & -1.15 & 0.28 & $-1.33--0.97$ & $<0.001$ & 0.81 & 0.30 & $0.62-1.01$ & $<0.001$ \\
\hline 50 & -0.70 & 0.29 & $-0.87--0.50$ & $<0.001$ & 0.37 & 0. & $0.17-0.57$ & 0.002 \\
\hline 65 & -0.22 & 0.29 & $-0.40--0.02$ & 0.027 & -0.08 & 0.32 & $-0.28-0.12$ & 0.388 \\
\hline 75 & 0.13 & 0.31 & $-0.07-0.32$ & 0.195 & -0.43 & 0.34 & $-0.65--0.21$ & 0.001 \\
\hline 85 & 0.55 & 0.30 & $0.35-0.74$ & $<0.001$ & -0.86 & 0.33 & $-1.06--0.64$ & $<0.001$ \\
\hline 95 & 1.28 & 0.31 & $1.08-1.48$ & $<0.001$ & -1.60 & 0.36 & $-1.84--1.37$ & $<0.001$ \\
\hline
\end{tabular}

$\mathrm{Cl}$, Confidence interval; SD, Standard deviation.

Moyers [5] recommended using the 75th percentile level of probability in his tables to predict mesio-distal widths of un-erupted permanent teeth, however, previous studies showed that Moyers' probability tables are not an accurate method for the prediction of mesio- distal widths of un-erupted permanent teeth in different populations [18-28,30-36].

In the present study there were no statistically significant differences between the sum of the sizes of the canines and premolars predicted by our equations and

Table 4 The mean difference (in $\mathrm{mm}$ ) between the predicted values of the sum of maxillary canines and premolar teeth of the present study and those predicted from Moyers' tables [5] for the same subjects at deferent percentiles (5- 95\%)

\begin{tabular}{|c|c|c|c|c|c|c|c|c|}
\hline \multirow{2}{*}{$\begin{array}{l}\text { Percentile } \\
\text { probability } \\
\%\end{array}$} & \multicolumn{4}{|l|}{ Girls $(n=135)$} & \multicolumn{4}{|l|}{ Boys $(n=85)$} \\
\hline & Mean difference $(\mathrm{mm})$ & SD & $95 \% \mathrm{Cl}$ & $P$ value & Mean difference $(\mathrm{mm})$ & SD & $95 \% \mathrm{Cl}$ & $P$ value \\
\hline 5 & -2.47 & 0.47 & $-2.77--2.17$ & $<0.001$ & -1.61 & 0.08 & $-1.66--1.56$ & $<0.001$ \\
\hline 15 & -1.81 & 0.48 & $-2.12--1.51$ & $<0.001$ & -1.09 & 0.07 & $-1.14--1.04$ & $<0.001$ \\
\hline 25 & -1.44 & 0.49 & $-1.75--1.12$ & $<0.001$ & -0.79 & 0.07 & $-0.84--0.74$ & $<0.001$ \\
\hline 35 & -1.14 & 0.49 & $-1.45--0.82$ & $<0.001$ & -0.54 & 0.09 & $-0.59--0.48$ & $<0.001$ \\
\hline 50 & -0.74 & 0.49 & $-1.05--0.42$ & $<0.001$ & -0.20 & 0.06 & $-0.25--0.16$ & $<0.001$ \\
\hline 65 & -0.33 & 0.50 & $-0.65--0.01$ & 0.044 & 0.11 & 0.08 & $0.06-0.16$ & 0.001 \\
\hline 75 & -0.02 & 0.49 & $-0.34-0.29$ & 0.865 & -1.30 & 5.73 & $-4.96-2.36$ & 0.451 \\
\hline 85 & 0.34 & 0.51 & $0.01-0.66$ & 0.041 & 0.67 & 0.10 & $0.60-0.74$ & $<0.001$ \\
\hline 95 & -0.67 & 5.94 & $-4.45-3.10$ & 0.702 & 1.20 & 0.10 & $1.14-1.27$ & $<0.001$ \\
\hline
\end{tabular}

$\mathrm{Cl}$, Confidence interval; SD, Standard deviation. 
Table 5 The mean difference (in $\mathrm{mm}$ ) between the predicted values of the sum of the permanent canines and the first and second premolars (345) of Ugandan subjects and those predicted from Tanaka and Johnston equation (0.5 Sum of lower incisor widths plus $\mathbf{1 1}$ for the upper $\mathbf{3 4 5}$ or $\mathbf{0 . 5}$ the sum of the lower incisor widths plus $\mathbf{1 0 . 5}$ for the lower $\mathbf{3 4 5 \text { ) }}$ [14] for the same subjects

\begin{tabular}{lllll}
\hline Sex & Arch & Mean difference & Standard deviation & 95\% Confidence interval of the difference \\
\hline Total & Maxillary canine and premolars & $0.75^{*}$ & 0.11 & $0.66-0.81$ \\
& Mandibular canine and premolars & $-0.70^{*}$ & 0.25 & $-0.86--0.53$ \\
Boys & Maxillary canine and premolars & $-0.85^{*}$ & 0.10 & $-0.91--0.78$ \\
& Mandibular canine and premolars & $-0.53^{*}$ & 0.22 & $-0.67--0.38$ \\
Girls & Maxillary canine and premolars & $-0.98^{*}$ & 0.12 & $-1.06--0.90$ \\
& Mandibular canine and premolars & $-0.80^{*}$ & 0.33 & $-1.02--0.59$ \\
\hline
\end{tabular}

*P-value $<0.05$.

the predicted widths from Moyers' tables [4] at the $65^{\text {th }}$ and $75^{\text {th }}$ percentile levels of probability in boys and girls, respectively, in the mandibular arch (Table 3). Furthermore, we observed no statistical significant differences between the sum of the sizes of the maxillary canine and premolars predicted from our equation and the predicted width from Moyers' tables [5] at $75^{\text {th }}$ percentile level of probability in boys as well as $75^{\text {th }}$ and $95^{\text {th }}$ levels in girls (Table 4). This is an indication that Moyers' probability tables can be used to predict un-erupted tooth widths in a Ugandan population at those particular percentile levels of probability. In a previous study in the Jordanian population [28], it was found that Moyers' probability tables [5] for prediction of sizes of unerupted permanent teeth can be applied at $65^{\text {th }}$ and $75^{\text {th }}$ levels in male and at the $85^{\text {th }}$ level in female subjects for both maxillary and mandibular arches. However, in the Saudi Arabian population [24], the most accurate width of un-erupted permanent canine and premolars was predicted at $50^{\text {th }}$ percentile level of probability as compared to the most commonly used $75^{\text {th }}$ level when both sexes are combined. These variations in percentile levels of probability used in predicting the most accurate tooth widths call for the need to develop regression equations for the different populations.

It is evident from the findings of the present study (Table 5) that the Tanaka and Johnston technique [14] overestimates the actual size of the Ugandan tooth widths. This overestimation can partly be explained by racial differences between the present study and that of Tanaka and Johnston [14]. However, our finding is in support of some previous workers $[18,19,33]$ who also reported an overestimation of the size of unerupted canines and premolars when using the Tanaka and Johnston prediction equations [14]. On the other hand, other workers [28] reported an underestimation of the actual mesio-distal widths of un-erupted permanent teeth when using the same technique. It can therefore be concluded that because of the differences in mesio-distal widths of mandibular incisors, mandibular and maxillary canines and premolars among different racial groups, data collected from one ethnic group for the purpose of predicting the size of un-erupted permanent teeth might generally, not be applicable to another [18].

\section{Conclusions}

Moyers' probability tables could accurately be used to predict tooth widths of Ugandan population at the $65^{\text {th }}$ and $75^{\text {th }}$ percentile levels of probability in boys and girls, respectively, in the mandibular arch, and at $75^{\text {th }}$ level in the boys as well as $75^{\text {th }}$ and $95^{\text {th }}$ levels in girls in the maxillary arch. However, the Tanaka and Johnston prediction equation overestimates the actual size of tooth widths of the Ugandan population.

\section{Competing interests}

The authors declare that they have no competing interests.

\section{Authors' contributions}

WB participated in measurement of tooth widths on dental casts and manuscript writing. AK and ML participated in data analysis and manuscript writing. CMR conceived the idea of study and participated in its design and coordination. All authors read and approved the final manuscript.

\section{Acknowledgement}

The authors are grateful to the children who participated in the study. Peter Emorut, of the Dental Laboratory, College of Health Sciences assisted in pouring the dental casts. The study was financially supported by Sida/SAREC.

\section{Author details}

${ }^{1}$ Department of Anatomy, College of Health Sciences, Makerere University, Kampala, Uganda. ${ }^{2}$ Department of Dentistry, College of Health Sciences, Makerere University, Kampala, Uganda.

\section{Received: 7 December 2010 Accepted: 23 July 2012}

Published: 23 July 2012

\section{References}

1. Hunter WS: Application of analysis of crowding and spacing of the teeth. Dent Clin. North Am 1978, 22:563-577.

2. Huckaba GW: Arch size analysis and tooth size perdition. Dent. Clin. North Am 1964, 8:431-440.

3. Smith HP, King DL, Valencia R: A comparison of three methods of mixed dentition analyses. J Pedod 1979, 3:291-302.

4. Staley RN, O'Gorman TW, Hoag JF, Shelly TH: Prediction of the widths of un-erupted canines and premolars. J Am Dent Assoc 1984, 108:185-190.

5. Moyer RE: Handbook of orthodontics. 4th edition. Chicago: Year Book; 1998:235-239. 
6. Staley HP, Hoag J: Prediction of the mesio-distal with of maxillary permanent canines and premolars. Am J Orthod 1978, 73:169-77.

7. Nance HN: The limitations of orthodontic treatment: Mixed dentition diagnosis and treatment. Am J Orthod 1947, 33:177-223.

8. Foster RR, Wylie WL: Arch length deficiency in the mixed dentition. Am J Orthod 1958, 44:464-476.

9. Ballard ML, Wylie W: Mixed dentition case analysis-estimating size of unerupted permanent teeth. Am J Orthod 1947, 33:754-559.

10. Cohen ME: Recognition of the developing Malocclusion. Dent. Clin. North Am 1959, 6:299-311.

11. Hixon EH, Oldfather RE: Estimation of the size of un-erupted cuspid and bicuspid teeth. Angle Orthod 1958, 22:236-240.

12. Sim JM: Minor tooth movement in children. 2nd edition. St. Louis: Mosby; 1977:74-81

13. Moorrees CFA, Reed RB: Correlation among crown diameters of human teeth. Arch. Oral Biol 1964, 9:685-697.

14. Tanaka MM, Johnston LE: The prediction of un-erupted canines and premolars in a contemporary population. J. Am. Den.t Assoc 1974, 88:798-801.

15. Brown JE: Predicting the mesio-distal crown width of un-erupted maxillary canines, first and second premolars. Master's Thesis. University of Tennessee, School of Dentistry, Memphis; 1955

16. Fonsenca CC: Predicting the mesio-distal crown width of the canine-premola segment of maxillary dental arches. Master's Thesis. University of Tennessee, School of Dentistry, Memphis; 1961.

17. Ferguson FS, Marco DJ, Sonnenburg EM, Shakun ML: The use of regression constants in estimating tooth size in the Negro population. Am J Orthod 1978, 73:68-72.

18. Al-Khadra $\mathrm{BH}$ : Prediction of the size of un-erupted canines and premolars in a Saudi Arab population. Am J Orthod Dentofac Orthop 1993, 104:369-372.

19. Yuen KK, Tang EL, So LL: Mixed dentition analysis for Hong Kong Chinese. Angle Orthod 1998, 68:21-28.

20. Van-der-Merwe SW, Rossouw P, Van-Wyk-Kotze TJ, Trutero H: An adaptation of the mixed dentition space analysis for a Western Cape Caucasian population. J Dent Assoc South Afri 1991, 46:475-479.

21. Motokawa W, Onzaki M, Soejima $Y$, Yoshida $Y$ : A method of mixed dentition analysis in the mandible. J Dent Child 1987, 54:114-118.

22. Ziberman $Y$, Koyoumdjisky KE, Vardimon A: Estimation of mesio-distal width of permanent canines and premolars in the early mixed dentition. J Dent Res 1977, 56:911-915.

23. Buwembo W, Luboga S: Moyer's method of mixed dentition analysis: a meta-analysis. Afri Health Sci 2004, 41:63-66.

24. Hashim HA, Al-Shalan TA: Prediction of the sizes of un-erupted permanent canines and premolars in a Saudi sample: A pilot study. J Contemp Dent Pract 2003, 4:40-53.

25. Lavelle CLB: Maxillary and mandibular tooth size in different racial groups and in different occlusal categories. Am J Orthod Dentofac Orthop 1972, 61:29-37.

26. Abdul WN, Dietmar G, Mohammad NK, Christian S: New regression equations for predicting the size of unerupted canines and premolars in a contemporary population. Angle Orthod 2002, 72:216-221.

27. World Medical Association: Declaration of Helsinki, version VI. http://www. wma.net/e/policy/b3.htm. Accessed on 25 May 2012.

28. Aahaija ESA, Qudeimat MA: Mixed dentition space analysis in Jordanian population: comparison of two methods. Int J Peadiatr Dent 2006, 16:104-110.

29. Portney LG, Watkins MP: Foundations of clinical research Applications to practice. New Jersey: Prentice Hall Inc; 2000:560-567.

30. Memon S, Fida M: Development of a prediction equation for the estimation of mandibular canine and premolar widths from mandibular first permanent molar and incisor widths. Eur J Orthod 2012, 34:340-4.

31. Melgaço CA, de Sousa Araújo MT, de Oliveira Ruellas AC: Mandibular permanent first molar and incisor width as predictor of mandibular canine and premolar width. Am J Orthod Dentofac Orthop 2007, 132:369-372.

32. Franzel HH, Benz EM: Mixed dentition analysis for black Americans. Pediatr Dent 1986, 8:226-230.

33. Jaroontham J, Godfrey K: Mixed dentition space analysis in a Thai population. Eur J Orthod 2000, 22:127-134.
34. Diagne F, Diop-Ba K, Ngom Pl, Mbow K: Mixed dentition analysis in a Senegalese population: elaboration of prediction tables. Am J Orthod Dentofac Orthop 2003, 124:178-183.

35. Houston WJ: The analysis of errors in orthodontic measurements. Am J Orthod 1983, 8:382-9031.

36. Bishara SE, Jakobsen JR: Comparison of two nonradiographic methods of predicting permanent tooth size in the mixed dentition. Am J Orthod Dentofac Orthop 1998, 114:573-576.

doi:10.1186/1472-6831-12-23

Cite this article as: Buwembo et al:: Prediction of width of un-erupted incisors, canines and premolars in a Ugandan population: A cross sectional study. BMC Oral Health 2012 12:23.

\section{Submit your next manuscript to BioMed Central and take full advantage of:}

- Convenient online submission

- Thorough peer review

- No space constraints or color figure charges

- Immediate publication on acceptance

- Inclusion in PubMed, CAS, Scopus and Google Scholar

- Research which is freely available for redistribution 